Published in final edited form as:

Clin Cancer Res. 2012 October 15; 18(20): 5816-5828. doi:10.1158/1078-0432.CCR-12-1141.

\title{
Biomarkers of Response to Akt Inhibitor MK-2206 in Breast Cancer
}

\author{
Takafumi Sangai ${ }^{1}$, Argun Akcakanat ${ }^{1}$, Huiqin Chen $^{2}$, Emily Tarco ${ }^{1,2}$, Yun Wu$^{3}$, Kim-Anh \\ Do $^{4}$, Todd W. Miller ${ }^{6}$, Carlos L. Arteaga ${ }^{6,7}$, Gordon B. Mills ${ }^{5}$, Ana Maria Gonzalez-Angulo ${ }^{2,5}$, \\ and Funda Meric-Bernstam ${ }^{1}$ \\ ${ }^{1}$ Department of Surgical Oncology, The University of Texas MD Anderson Cancer Center, \\ Houston, Texas \\ ${ }^{2}$ Department of Breast Medical Oncology, The University of Texas MD Anderson Cancer Center, \\ Houston, Texas \\ ${ }^{3}$ Department of Pathology, The University of Texas MD Anderson Cancer Center, Houston, \\ Texas \\ ${ }^{4}$ Department of Biostatistics, The University of Texas MD Anderson Cancer Center, Houston, \\ Texas \\ ${ }^{5}$ Department of Systems Biology, The University of Texas MD Anderson Cancer Center, Houston, \\ Texas \\ ${ }^{6}$ Department of Cancer Biology, Medicine, Vanderbilt-Ingram Comprehensive Cancer Center, \\ Vanderbilt University, Nashville, Tennessee \\ ${ }^{7}$ Department of Medicine, Vanderbilt-Ingram Comprehensive Cancer Center, Vanderbilt \\ University, Nashville, Tennessee
}

\section{Abstract}

Purpose-We tested the hypothesis that allosteric Akt inhibitor MK-2206 inhibits tumor growth, and that PTEN/PIK3CA mutations confer MK-2206 sensitivity.

(C)2012 American Association for Cancer Research.

Corresponding Author: Funda Meric-Bernstam, Department of Surgical Oncology, The University of Texas MD Anderson Cancer Center, 1400 Pressler Street, Unit 1484, Houston, TX 77030-4009. Phone: 713-745-4453; Fax: 713-745-4926;

fmeric@mdanderson.org.

Supplementary data for this article are available at Clinical Cancer Research Online (http://clincancerres.aacrjournals.org/).

Disclosure of Potential Conflicts of Interest

No potential conflicts of interest were disclosed.

Authors' Contributions

Conception and design: T. Sangai, A.M. Gonzalez-Angulo, F. Meric-Bernstam

Development of methodology: T. Sangai, K.-A. Do, G.B. Mills, A.M. Gonzalez-Angulo, F. Meric-Bernstam

Acquisition of data ( provided animals, acquired and managed patients, provided facilities, etc.): T. Sangai, A. Akcakanat, T.W. Miller, C.L. Arteaga, F. Meric-Bernstam

Analysis and interpretation of data (e.g., statistical analysis, biostatistics, computational analysis): T. Sangai, H. Chen, Y. Wu, K.-A. Do, G.B. Mills, A.M. Gonzalez-Angulo, F. Meric-Bernstam

Writing, review, and/or revision of the manuscript: T. Sangai, A. Akcakanat, Y. Wu, K.-A. Do, T.W. Miller, G.B. Mills, A.M.

Gonzalez-Angulo, F. Meric-Bernstam

Administrative, technical, or material support (i.e., reporting or organizing data, constructing databases): T. Sangai, E. Tarco,

F. Meric-Bernstam

Study supervision: G.B. Mills 
Experimental Design-MK-2206 effects on cell signaling were assessed in vitro and in vivo. Its antitumor efficacy was assessed in vitro in a panel of cancer cell lines with differing PIK3CA and PTEN status. Its in vivo efficacy was tested as a single agent and in combination with paclitaxel.

Results-MK-2206 inhibited Akt signaling and cell-cycle progression, and increased apoptosis in a dose-dependent manner in breast cancer cell lines. Cell lines with PTEN or PIK3CA mutations were significantly more sensitive to MK-2206; however, several lines with PTEN/ PIK3CA mutations were MK-2206 resistant. siRNA knockdown of PTEN in breast cancer cells increased Akt phosphorylation concordant with increased MK-2206 sensitivity. Stable transfection of PIK3CA E545K or H1047R mutant plasmids into normal-like MCF10A breast cells enhanced MK-2206 sensitivity. Cell lines that were less sensitive to MK-2206 had lower ratios of Akt1/Akt2 and had less growth inhibition with Akt siRNA knockdown. In PTEN-mutant ZR75-1 breast cancer xenografts, MK-2206 treatment inhibited Akt signaling, cell proliferation, and tumor growth. In vitro, MK-2206 showed a synergistic interaction with paclitaxel in MK-2206-sensitive cell lines, and this combination had significantly greater antitumor efficacy than either agent alone in vivo.

Conclusions-MK-2206 has antitumor activity alone and in combination with chemotherapy. This activity may be greater in tumors with PTEN loss or PIK3CA mutation, providing a strategy for patient enrichment in clinical trials.

\section{Introduction}

PI3K/Akt/mTOR signaling plays key roles in cell growth, protein translation, autophagy, metabolism, and cell survival (1). Activation of Akt signaling contributes to the pathogenesis of cancer. PTEN is mutated in many tumor types, and PTEN expression is decreased in many cancers, including sporadic breast cancer. Mutations in the PIK3CA gene, which encodes the catalytic subunit of PI3K, have been reported in many cancer types, and occur in more than $20 \%$ of breast cancers (2).

Although controversial, breast cancers with an increased level of Akt phosphorylation/ activation or a gene expression signature of PTEN loss have been proposed to have a poor outcome (3). Although PIK3CA mutations have not been uniformly associated with activation of Akt signaling in patient tumors $(2,4)$, several PIK3CA mutations have been shown to have a gain-of function, leading to an increase in Akt phosphorylation in preclinical models $(5,6)$. The existing preclinical data suggest that most tumors expressing a low level of PTEN and many with a mutant PIK3CA rely on Akt for oncogenic signaling. Loss of PTEN activity and activation of phosphatidylinositol 3-kinase (PI3K) signaling are associated with resistance to endocrine therapy $(7,8)$, and resistance to trastuzumab $(9-11)$. Thus, Akt is a very promising target for breast cancer therapy.

MK-2206 (Merck Oncology) is a novel selective allosteric inhibitor of Akt. Phase II clinical trials of MK-2206 have begun for the treatment of a variety of tumor types, including breast cancer. Thus, there is a pressing need to better understand the antitumor efficacy of this novel compound, both when used alone and in combination regimens, and to define markers that predict benefit from this agent. We sought to determine the antitumor efficacy of MK-2206 in breast cancer cell lines with varying genetic backgrounds. Our data show that MK-2206 inhibited Akt signaling and cell-cycle progression, and increased apoptosis in a dose-dependent manner. MK-2206 sensitivity was significantly greater in cell lines with PTEN loss or PIK3CA mutation. In MK-2206-sensitive cells, MK-2206 was synergistic with paclitaxel. MK-2206 also had a dose-dependent growth-inhibitory effect in vivo, and enhanced the antitumor activity of paclitaxel. 


\section{Materials and Methods}

\section{Cell lines and cultures}

Cell lines were obtained from American Tissue Culture Collection: BT474, MCF7, HCC70, HCC1954, HT29, MCF10A, MCF12A, MDA-MB-231, MDA-MB-435, MDA-MB-453, MDA-MB-468, NCI/H727, SKBR3, U87MG, and ZR75-1. NCI/ADR-RES cells were obtained from the National Cancer Institute. MCF7 cells stably transfected with PTEN small hairpin RNA (shRNA) or mismatch control shRNA were cultured with $1 \mu \mathrm{g} / \mathrm{mL}$ of puromycin (7). Before starting experiment, these cells were cultured in phenol red-free medium supplemented with $2 \%$ charcoal-stripped FBS for 24 hours. PIK3CA p110 wildtype, E545K mutant, and H1047R mutant plasmids were stably transfected into MCF10A cells and cultured with $4 \mu \mathrm{g} / \mathrm{mL}$ of blasticidin. All cell lines were passaged less than 6 months after resuscitation and authenticated by vendors.

\section{Reagents}

MK-2206 was provided by Merck and Co., Inc. and used in all in vitro studies and most in vivo studies. In vivo studies in BT474 and MCF7 were conducted with MK-2206 produced in-house. For in vivo experiments, 30\% Captisol (CYDEX Pharmaceuticals) was used as a vehicle. Rapamycin was purchased from LC Laboratories, Inc.

\section{Cell growth assay}

Antiproliferative activity was tested by sulforhodamine B (SRB) assay (12). The median inhibitory concentration $\left(\mathrm{IC}_{50}\right)$ and combination index $(\mathrm{CI})$ were determined from doseresponse curves for 4 days treatment (13).

\section{Cell-cycle analysis and annexin $\mathrm{V}$ binding assay}

For cell cycle assay, cells that were attached to the petridish and floating cells were collected. Samples were analyzed by flow cytometry and ModFit LT software (Verity Software House). Apoptosis was identified by using the annexin V apoptosis kit (Roche) according to the manufacturer's protocol, and cells were analyzed by flow cytometry and FlowJo (Tree Star; 13).

SIRNA

siRNA duplexes (Sigma) were used to silence PTEN (14). Negative control siRNA was purchased from Life Technologies Co. Akt1-, Akt2-, and Akt3-specific siRNA pool, nontargeting pool siRNA, and DharmaFECT transfection reagent were purchased from Thermo Fisher Scientific, Inc.

\section{Reverse-phase protein arrays}

Reverse-phase protein array (RPPA) analysis was conducted as described previously (1517). Cell lines were treated with MK-2206 (50 nmol/L, $150 \mathrm{nmol} / \mathrm{L}, 500 \mathrm{nmol} / \mathrm{L}$, and 5 $\mu \mathrm{mol} / \mathrm{L}$ ) or $0.1 \%$ dimethyl sulfoxide (DMSO) for 24 hours. Each condition was carried out in 3 biologic replicates.

\section{Multiplex phosphoprotein assays}

Xenograft samples were lysed in RPPA lysis buffer. Final protein concentration was corrected to $1 \mu \mathrm{g} / \mu \mathrm{L}$. Akt, pAkt S473, pGSK3 $\beta$ S9 were measured by MSD (Meso Scale Discovery) assay following the vendor's instructions. 


\section{Western blotting}

Immunoblotting was conducted as described previously (18) with the following antibodies: Akt, Akt1, Akt2, Akt3, pAktT308, pAktS473, GSK3ß, pGSK3ß S9, pPRAS40T246, pFOXO1/FOXO3a T24/T32, pBad S112, pBad S136, mTOR, pmTOR S2448, S6K, pS6K T389, pS6 S235/236, 4E-BP1, p4E-BP1 T37/46, p4E-BP1 S65, p4E-BP1 T70, PTEN (Cell Signaling Technology, Inc.), PHLPP1, PHLPP2 (Bethyl Laboratories, Inc.), actin (SigmaAldrich), INPP4B (Santa Cruz Biotechnology), pmTOR S2481 (Millipore), and vinculin (Abcam).

\section{Immunohistochemistry and terminal deoxynucleotidyl transferase dUTP nick end labeling assay}

Immunohistochemical analysis was conducted using pAkt S473 (Cell Signaling) and Ki67 antibodies (Dako) on the same samples as MSD assay and Western blotting from the first in vivo study $(n=4)$.

For detection of apoptosis, tissue sections of formalin-fixed, paraffin-embedded xenografts were stained using Peroxidase In Situ Apoptosis Detection Kit (Millipore) following the manufacturer's instructions.

\section{In vivo studies}

All animal experiments were approved by the MD Anderson Animal Care and Use Committee. ZR75-1 $\left(1 \times 10^{7}\right)$, MCF7 $\left(5 \times 10^{6}\right)$, and BT474 $\left(5 \times 10^{6}\right)$ cells were inoculated in the mammary fat pads of female nu/nu mice (Department of Experimental Oncology, MD Anderson). MCF7 and BT474 cell suspensions were mixed with Matrigel (BD Biosciences). All mice were implanted with 17 $\beta$-estradiol pellets (Innovative Research of America) subcutaneously. More than one mice death in the study arm was considered toxicity.

In the single-agent MK-2206 treatment experiment, the mice bearing ZR75-1 xenografts were randomized into 3 groups (vehicle, MK-2206 $240 \mathrm{mg} / \mathrm{kg}$, or $480 \mathrm{mg} / \mathrm{kg}, n=5-6$ ). The mice bearing MCF7 and BT474 xenografts were randomized into 2 groups (MCF7: vehicle and MK-2206 $360 \mathrm{mg} / \mathrm{kg}, n=7$; and BT474: vehicle and MK-2206 $360 \mathrm{mg} / \mathrm{kg}, n=6$ ).

To determine the in vivo efficacy of MK-2206 in combination with paclitaxel, mice were randomized into 4 groups (vehicle, $15 \mathrm{mg} / \mathrm{kg}$ paclitaxel, $360 \mathrm{mg} / \mathrm{kg} \mathrm{MK}-2206$, or both, $n=$ 7 ). In the second combination therapy experiment, the mice were randomized into 5 groups (vehicle, $5 \mathrm{mg} / \mathrm{kg}$ paclitaxel, $240 \mathrm{mg} / \mathrm{kg}$ MK-2206, both simultaneously, or paclitaxel followed by MK-2206 24 hours later, $n=6-8$ ).

All of the treatments were given weekly in these 3 experiments. Tumor volumes were calculated as previously described (13). Mice were euthanized 24 hours after the last treatment, and half of each tumor was snap-frozen and the other half was fixed in formalin and embedded in paraffin.

To determine whether apoptosis is induced in vivo by MK-2206 and paclitaxel, the mice bearing ZR75-1 tumor were randomized into 5 groups [vehicle, $15 \mathrm{mg} / \mathrm{kg}$ paclitaxel, 360 $\mathrm{mg} / \mathrm{kg}$ MK-2206, paclitaxel (15 mg/kg) and MK-2206 (360 mg/kg), and $480 \mathrm{mg} / \mathrm{kg}$ MK-2206, $n=3-4]$. All of the treatments were given once only in this experiment. Mice were euthanized 48 hours after the treatment and tumors were fixed in formalin and embedded in paraffin. 


\section{Statistical analysis}

For in vitro studies, comparison between 2, and multiple, groups were carried out by the Student $t$ test and 1-way ANOVA followed by Tukey multiple comparison test, respectively.

An isotonic regression model was used to identify a subset of proteins that had a monotone relationship between protein expression and dosage [false discovery rate (FDR) $<0.3$; refs. 19 and 20].

Association between PIK3CA/PTEN mutation status and MK-2206 sensitivity was tested with Fisher exact test. For the in vivo study, pairwise $t$ tests were adjusted by the FDR method. The Tukey and FDR methods were used to adjust for multiplicities. All in vitro experiments were conducted at least 3 times. Data were presented as means \pm SE.

\section{Results}

\section{MK-2206 inhibits Akt signaling}

MK-2206 is a novel allosteric Akt inhibitor with selective activity against Akt1 and Akt2 (21). To determine the effect of MK-2206 on cell signaling, we assessed the effect of MK-2206 on the functional proteomic profiles of 7 breast cancer cell lines of different subtypes and genetic backgrounds. RPPA showed a dose-dependent decrease in the expression of 10 markers, including pAkt T308 and pAkt S473 (FDR < 0.3, Supplementary Table S1), and Akt downstream signaling (Fig. 1A).

To further study the effects of MK-2206 treatment dose and duration, we treated ZR75-1 breast cancer cells, a cell line with a hemizygous deletion of PTEN and a missense mutation in the remaining allele (22), with either rapamycin (100 nmol/L), an allosteric mTOR inhibitor, or increasing doses of MK-2206 for 24 hours (Fig. 1B). An MK-2206 concentration of $50 \mathrm{nmol} / \mathrm{L}$, a concentration that is clinically achievable in plasma (23), led to decreases in pAkt T308 and pAkt S473 levels and inhibited Akt signaling. Inhibition of Akt activity was confirmed by dose-dependent decreases in phosphorylation of Akt downstream targets GSK3 $\beta$, PRAS40, FOXO1/FOXO3a, and Bad. None of these nonmTOR-mediated signaling events was inhibited by rapamycin. Phosphorylation of mTOR target S6K and its target S6 were inhibited by MK-2206, although not as robustly as by rapamycin. In contrast, high doses MK-2206 (500 nmol/L and 5,000 nmol/L) inhibited 4EBP1 phosphorylation more than rapamycin.

To determine the time course of MK-2206 effects, ZR75-1 cells were treated with MK-2206 $150 \mathrm{nmol} / \mathrm{L}$ and collected after 1, 2, 6, 24, and 48 hours (Fig. 1C). MK-2206 inhibited Akt phosphorylation and downstream signaling within 1 hour, and this inhibition continued for at least 48 hours in terms of pAkt levels. Intriguingly, mTOR targets S6K/S6 and 4E-BP1 returned to baseline phosphorylation at delayed time points despite continued inhibition of pAkt, potentially representing other signaling pathways integrating with mTOR signaling.

\section{MK-2206 inhibits cell cycle and induces apoptosis}

The effect of MK-2206 on cell-cycle progression was analyzed by flow cytometry (Fig. 1D). Breast cancer cell lines were treated with vehicle, rapamycin, or MK-2206 for 4 days, and percentages of cells in $\mathrm{G}_{1}, \mathrm{~S}$, and $\mathrm{G}_{2}-\mathrm{M}$ phases of the cell cycle were determined. Both MK-2206 and rapamycin significantly inhibited cell-cycle progression from $\mathrm{G}_{1}$ to $S$-phase in ZR75-1 and MCF7 cells, but not in MDA-MB-231 cells, which were resistant to both agents. In MDA-MB-468, rapamycin significantly increased the percentage of cells in $\mathrm{G}_{1}$ phase, but MK-2206 did not. 
To determine whether MK-2206 induces apoptosis, 3 of the most MK-2206-sensitive breast cancer cell lines were treated with vehicle or increasing concentrations of MK-2206 for 3 days, and the percentages of annexin V-positive cells were determined (Fig. 1E). High doses MK-2206 (500 nmol/L and 5,000 nmol/L) significantly induced apoptotic cell death in all 3 cell lines.

\section{Sensitivity to MK-2206 is associated with PTEN and PIK3CA status}

We tested the MK-2206 sensitivity of 16 cell lines; the panel was enriched for breast cancer cell lines, and consisted of cell lines with varying genotypes and a range of sensitivity to allosteric mTOR inhibitor rapamycin (24). MK-2206 sensitivity was assessed by SRB assay (Fig. 2A). Five of the cell lines were sensitive to MK-2206 (defined as greater than 50\% growth inhibition at concentrations less than $500 \mathrm{nmol} / \mathrm{L}$ ); all 5 had either a PIK3CA or PTEN mutation. Overall, 5 of 9 cell lines that had PIK3CA and/or PTEN mutation were MK-2206 sensitive, whereas none of the 7 PTEN/PI3KCA wild-type cell lines were MK-2206 sensitive $(P=0.0337$, Fig. 2B). One of the 5 MK-2206-sensitive cell lines had a $R A S$ or $R A F$ mutation, although 4 of the 11 resistant cell lines had a $R A S / R A F$ mutation ( $P$ = 1.0000). Notably ZR75-1 has a HRAS E162K mutation as well as a PTEN mutation whereas among the resistant cell lines there was 1 KRAS mutant, 2 BRAF mutants, and 1 with both mutations $(25,26)$.

To confirm this finding in a wider variety of cancer cell lines, we assessed the association between PTEN or PIK3CA mutation status and MK-2206 sensitivity in 444 cancer cell lines using the Catalogue of Somatic Mutations in Cancer (COSMIC) database (27). Cell lines had been treated with MK-2206 for 72 hours and their $\mathrm{IC}_{50}$ was recorded; we used the mean $\mathrm{IC}_{50}$ value of wild-type PTEN/PIK3CAasa cutoff for sensitivity as per their definition. Both PIK3CA and PTEN mutations were associated with increased MK-2206 sensitivity $(P=$ 0.0043 and $P 0.0062$, respectively; Fig. 2 C). Mean $\mathrm{IC}_{50}$ value of PIK3CA and PTEN mutant cell lines was also lower than wild type (Supplementary Fig. S1). In contrast, cell lines with $R A S / R A F$ mutations had higher MK-2206 $\mathrm{IC}_{50}$ (Supplementary Fig. S1).

As PTEN loss and PIK3CA mutations are relatively common in breast cancer $(2,28)$, we assessed the functional impact of these aberrations on in vitro MK-2206 sensitivity. To determine whether PTEN loss confers MK-2206 sensitivity, we assessed MK-2206 sensitivity in isogenic cell lines with differing expression levels of PTEN. We first studied MDA-MB-231, a triple-negative breast cancer cell line with normal PTEN levels and relative MK-2206 resistance. PTEN siRNA knockdown increased expression of pAkt S473 more than 3-fold compared with control siRNA, and this Akt activation caused an increase of pBad S136, a downstream target of Akt $(29,30)$. Increases in both pAkt and pBad were reversed by MK-2206 treatment (Fig. 3A). After PTEN knockdown with siRNA, growth of MDA-MB-231 cells was inhibited to a significantly greater extent by MK-2206 treatment than by control siRNA in 3 independent experiments. Similar results were observed in the HER2-positive breast cancer cell line SKBR3 (Fig. 3B).

Next, MCF7 cells stably transfected with mismatch control shRNA or PTEN shRNA were cultured in estrogen-depleted condition. Akt phosphorylation at both the T308 and S473 residues was increased in PTEN knockdown cells compared with mismatch control shRNA cells, and this was reversed by treatment with MK-220650 nmol/L. The $\mathrm{IC}_{50}$ of MK-2206 was significantly lower in MCF7 PTEN shRNA knockdown cells than in controls (Fig. 3C).

We next tested the effect of PIK3CA mutations on MK-2206 sensitivity. PIK3CA wild-type, E545K mutant, and H1047R mutant plasmids were stably transfected into normal-like breast epithelial cell line MCF10A. In the PIK3CA mutant-transfected cells, Akt phosphorylation at both T308 and S473 residues was increased compared with that in PIK3CA wild-type- 
transfected cells, and this was reversed by treatment with MK-2206 $500 \mathrm{nmol} / \mathrm{L}$ (Fig. 3D). The $\mathrm{IC}_{50}$ of MCF10A cell lines transfected with PIK3CA E545K or PIK3CA H1047R was significantly lower than that of PIK3CA wild-type cells (Fig. 3D).

\section{Cell lines sensitive to MK-2206 are also sensitive to Akt siRNA knockdown}

Not all cell lines with PIK3CA or PTEN aberrations were sensitive to MK-2206, thus we also assessed expression of Akt isoforms, Akt phosphorylation, and the expression of Akt phosphatases in MK-2206-sensitive and -resistant cell lines (Fig. 4A). Baseline Akt phosphorylation did not show a strong relationship to MK-2206 sensitivity. However, both cell lines without pAkt expression were MK-2206 resistant. PTEN expression was decreased or lost in 4 of 5 cell lines with PTEN mutations (31), suggesting that loss of PTEN expression can be used to select for tumors with PTEN mutations. Although PH domain leucine-rich repeat-containing protein phosphatases (PHLPP) and inositol polyphosphate 4phosphatase (INPP4B) have both been previously reported to regulate pAkt (32-34), PHLPP expression did not show an association with pAkt S473 expression or MK-2206 sensitivity (Fig. 4A). Contrary to our expectation, loss of INPP4B expression was observed in 4 of 9 MK-2206-resistant cell lines but in none of the MK-2206-sensitive cell lines;2 of these cell lines also did not express pAkt.

MK-2206 inhibits all 3 Akt isoforms, Akt1, Akt2, and Akt3, but is 5- to 10-fold less potent against Akt3 (IC 50 : Akt 5 nmol/L, Akt2 12 nmol/L, Akt3 65 nmol/L; 21). Furthermore, Akt isoforms have been proposed to have distinct and separate roles in tumorigenesis (35). Thus, we assessed the expression of different Akt isoforms in MK-2206-sensitive and more resistant cell lines (Fig. 4A). The ratio of Akt1 to Akt2 was significantly higher in MK-2206-sensitive cells (Fig. 4A, right panel). Some MK-2206-resistant cells expressed Akt3; however, this was insufficient to explain relative sensitivity to MK-2206. We then sought to determine whether the Akt isoform ratio was predictive of MK-2206 sensitivity in a larger panel of cell lines. For 296 cell lines, we obtained MK-2206 IC 50 data from the COSMIC and transcriptional profiling data from the Cancer Cell Line Encyclopedia (26). Akt1/Akt2 mRNA expression did not show correlation with MK-2206 sensitivity.

We tested the Akt dependence of the growth of MK-2206- sensitive and -resistant cell lines by Akt siRNA and SRB assay. Expression of Akt1, 2, and 3 isoforms was knocked down with isoform-specific siRNA as shown by Western blotting (Fig. 4B). Combined treatment with siRNA to Akt1 and Akt2 led to statistically significant inhibition of growth not only in MK-2206-sensitive cell line ZR75-1 (PTEN loss), but also in MK-2206-resistant cell lines MDA-MB-468 (PTEN loss), HCC1954 (PIK3CA mutation), and MDA-MB-231 (wild-type PTEN and PIK3CA; Fig. 4B). There was greater than 50\% suppression of cell growth in MK-2206- sensitive ZR75-1 cells but not in MK-2206-resistant cell lines. Knockdown of all 3 Akt isoforms in Akt3-expressing MDA-MB-231 still did not achieve greater than 50\% suppression of growth inhibition.

\section{MK-2206 inhibits Akt signaling and tumor growth in vivo}

To determine the effect of MK-2206 in vivo, nu/nu mice bearing ZR75-1 xenografts were treated orally with MK-2206 $240 \mathrm{mg} / \mathrm{kg}$ or $480 \mathrm{mg} / \mathrm{kg}$ once per week. Tumors were harvested 24 hours after the 4th treatment. Four tumors were randomly selected from each group and analyzed by multiplex proteomics (MSD) or Western blotting. MSD showed statistically significant inhibition of pAkt and its target pGSK3b (Fig. 5A). Western blotting showed a decrease in pAkt; with greater inhibition with the higher dose. There was an even greater dose-dependence of inhibition of downstream signaling targets such as pPRAS40, pBad, p4E-BP1, and pS6K (Fig. 5B); pAkt expression in the high- and low-dose MK-2206treated lysates may have been beyond the linear range of Western blotting and MSD assays. 
Immunohistochemical analysis showed inhibition of pAkt and a statistically significant decrease in proliferation marker Ki-67, again with greater effects with the higher MK-2206 dose (mean percentages of positive cells: control 85.0\%, MK-2206 240mg/kg72.5\%, and MK-2206480mg/kg52.5\%;Fig. 5C).

Both $240 \mathrm{mg} / \mathrm{kg}$ and $480 \mathrm{mg} / \mathrm{kg}$ MK-2206 weekly oral treatments inhibited tumor growth compared with vehicle control ( $P<0.0001$ for both comparisons; Fig. 5D). Tumors were significantly smaller in mice treated with MK-2206 $480 \mathrm{mg} / \mathrm{kg}$ than in those treated with $240 \mathrm{mg} / \mathrm{kg}(\mathrm{P}=0.0243)$, suggesting that MK-2206 has a dose-dependent growth-inhibitory effect in vivo.

To further investigate the antitumor effect of MK-2206 in vivo, nu/nu mice bearing MCF7 and BT474 xenografts were treated orally with MK-2206. Mice bearing MCF7 xenografts were treated with an initial dose of $480 \mathrm{mg} / \mathrm{kg}$ MK-2206; the dose was reduced to $360 \mathrm{mg} /$ $\mathrm{kg}$ weekly due to general fatigue. Mice bearing BT474 xenografts were treated with $360 \mathrm{mg} /$ kg MK-2206 weekly. MK-2206 treatment was associated with tumor growth inhibition but not tumor regression in MCF7 ( $P<0.0001$; Supplementary Fig. S2A) and BT474 xenografts $(P<0.0001$; Supplementary Fig. S2B). However, significant toxicity was observed in these 2 experiments in the study arms, with deaths in 3 of 7 mice in the MCF7 experiment ( 2 after second dose and 1 after third dose), and with deaths in 2 of 6 mice in the BT474 experiment, with none in the control groups. Unfortunately, autopsies were not obtained; thus cause of death is unknown. Notably, these studies were carried out at the same time, with the same mouse lot and with MK-2206 obtained from an alternate source (compound generated inhouse). As there were no deaths in previous experiments conducted with MK-2206 obtained from Merck at $360 \mathrm{mg} / \mathrm{kg}$ or $480 \mathrm{mg} / \mathrm{kg}$, it is possible that the formulations differed in amount, solubility, and ultimate drug concentrations achieved.

\section{MK-2206 is synergistic with paclitaxel in vitro and enhances paclitaxel's antitumor efficacy in vivo}

Next, we wanted to determine whether MK-2206 en-

hancestheeffectofpaclitaxel,anantimicrotubulechemother-apeutic agent commonly used for breast cancer treatment. Apoptosis induced by MK-2206 and paclitaxel, alone or in combination, was assessed by flow cytometry with annexin V labeling in ZR75-1 cells. After cells were treated for 72 hours, the population of annexin $\mathrm{V}$-positive cells was higher in paclitaxel + MK-2206-treated cells compared with cells treated with either agent alone (Fig. 6A). Apoptosis induced by treatment was calculated by subtracting the percentage of annexin $\mathrm{V}$-positive cells in vehicle-treated cells from the annexin $\mathrm{V}$-positive population in the treatment groups (Fig. 6B). The combination of paclitaxel $100 \mathrm{ng} / \mathrm{mL}+\mathrm{MK}-220650$ $\mathrm{nmol} / \mathrm{L}$ induced significantly more annexin V-positive cells than MK-2206 $50 \mathrm{nmol} / \mathrm{L}$ alone and paclitaxel alone.

We then tested whether there was an additive or synergistic treatment interaction between MK-2206 and paclitaxel in 5 breast cancer cell lines, 3 that were MK-2206 sensitive (ZR75-1, HCC70, MDA-MB-453) and 2 that were MK-2206 resistant (HCC1954, MDAMB-468). The cells were treated with a range of doses of MK-2206 and paclitaxel simultaneously for 96 hours. The effects on cell growth were assessed by SRB assay and CI values were calculated. MK-2206 and paclitaxel combination was synergistic $(\mathrm{CI}<1.0)$ in all 3 MK-2206-sensitive cell lines, but not in the 2 MK-2206-resistant cell lines tested (Fig. 6C). The synergy was greatest in ZR75-1 cells.

We next determined the in vivo effect of MK-2206 alone and in combination with paclitaxel. Terminal deoxynucleotidyl transferase-mediated dUTP nick end labeling (TUNEL) assay showed apoptosis induction in ZR75-1 xenografts harvested 48 hours after 
MK-2206 treatment and a statistically significant increase in apoptosis when MK-2206 is administered in combination with paclitaxel [mean positive cells at 10 fields $(\times 400$ magnification): vehicle 17.3, $15 \mathrm{mg} / \mathrm{kg}$ paclitaxel 66.0, $360 \mathrm{mg} / \mathrm{kg}$ MK-2206 68.7, $480 \mathrm{mg} /$ kg MK-2206 84.5, and 15 mg/kg paclitaxel and 360 mg/kg MK-2206 123.0; Fig. 6D].

For assessment of antitumor efficacy, nu/nu mice with ZR75-1 xenografts were treated weekly with vehicle, paclitaxel $15 \mathrm{mg} / \mathrm{kg}$ only, MK-2206 $360 \mathrm{mg} / \mathrm{kg}$ only, or the combination of paclitaxel and MK-2206 (Fig. 6E). Pairwise $t$ tests, which were adjusted by the FDR method, are shown. All 3 treatments significantly inhibited growth compared with controls ( $P<0.0001$ for all 3 comparisons). The combination of MK-2206 and paclitaxel inhibited growth significantly more than paclitaxel alone $(P=0.0196)$ or MK-2206 alone $(P$ $=0.0125$ ).

In our first in vivo experiment, 2 mice died after the third treatment (on day 17) in the combination arm. Therefore, we determined whether lower doses of MK-2206 and paclitaxel would also enhance the efficacy of paclitaxel in vivo. In addition, we explored the role of therapy sequence in this second experiment. In previous work, we found that rapamycin is synergistic with paclitaxel in vitro, and the antitumor efficacy is greater when rapamycin is given 24 hours after paclitaxel (13). It has been reported recently that MK-2206 is additive/synergistic in vitro with antimicrotubule agent docetaxel when MK-2206 and docetaxel are given simultaneously, but there is synergy when MK-2206 is given 24 hours after docetaxel (21). In our experiment, therefore, ZR75-1 xenografts were treated with a combination of paclitaxel and $240 \mathrm{mg} / \mathrm{kg}$ MK-2206 both synchronously and sequentially, with MK-2206 given 24 hours after paclitaxel (Fig. 6F). These treatments were well tolerated, with no symptoms or weight loss in the treatment groups. All 4 treatments (paclitaxel alone, MK-2206 alone, and synchronous or sequential paclitaxel+MK-2206) inhibited growth compared with vehicle $(\mathrm{P}<0.0001)$. Synchronous treatment with paclitaxel and MK-2206 inhibited growth significantly compared with paclitaxel alone $(P=0.0033)$ or MK-2206 alone $(P=0.0037)$. Sequential treatment with paclitaxel followed by MK-2206 also inhibited growth significantly compared with paclitaxel alone $(P=0.0159)$ or MK-2206 alone $(P=0.0159)$. Tumor growth inhibition did not differ significantly in mice treated with paclitaxel and MK-2206 synchronously versus sequentially.

\section{Discussion}

Activated Akt signaling is a significant contributor to the pathogenesis of cancer. PTEN is a negative regulator of PI3K/Akt signaling whose expression is decreased in many tumor types, and PIK3CA is frequently mutated in many human cancers. MK-2206 is a selective allosteric inhibitor of Akt; we sought to determine the antitumor efficacy of MK-2206 in cell lines of varying genetic backgrounds. We show here that MK-2206 inhibits Akt signaling and cell-cycle progression, and increases apoptosis in a dose-dependent manner. MK-2206 sensitivity was significantly greater in cell lines with PTEN or PIK3CA mutation; however, not all lines with aberrations were sensitive. MK-2206 also had a growth-inhibitory effect in vivo, and enhanced the antitumor activity of paclitaxel.

There are several ongoing clinical trials of MK-2206 in multiple tumor types. Thus, there is a pressing need to identify predictive markers for selection of patients most likely to benefit. Although in our panel, $R A S / R A F$ mutations were not associated with resistance to MK-2206. They were associated with increased resistance in the COSMIC cell line set; this finding is worthy of further exploration. In our study, cell lines with PTEN or PIK3CA mutations were more likely to be sensitive to MK-2206. Furthermore, loss of PTEN or transfection with mutant PIK3CA conferred greater MK-2206 sensitivity. Similarly, transfection of PIK3CA mutants was recently shown to enhance MK-2206 sensitivity of 
thyroid cancer cell line SW176 (36). These findings provide support for use of PTEN mutation/loss or PIK3CA mutations as potential predictive biomarkers of response, and their use for patient enrichment in ongoing clinical trials [e.g.,NCT01277757, Phase II Trial of Akt Inhibitor MK-2206 in Patients With Advanced Breast Cancer Who Have Tumors With a PIK3CA Mutation and/or PTEN Loss (37)].

Previously, we showed by immunohistochemical analysis that PTEN expression was lost in $30 \%$ of primary breast tumors and $25 \%$ of breast cancer metastases (28). PIK3CA mutations were detected in $40 \%$ of primary breast tumors and $42 \%$ of metastases. Thus, these aberrations are common enough to make their use for patient selection feasible. However, there was 26\% discordance in PTEN expression status and 18\% discordance in PIK3CA mutation status between primary and metastatic tumors. This high degree of discordance in PTEN level and PIK3CA mutations between primary tumors and metastases may have implications for patient selection in Akt-targeted therapy trials. Although primary tumor PIK3CA and PTEN status can be used to enrich for patients likely to have PIK3CA and PTEN alterations in their metastases, biopsy of the metastases may help confirm the metastatic tumor biomarker status and to determine whether patients with alterations that are preserved in both the primary and the metastases are more responsive to Akt-targeted therapy. It is notable that in our study not all cell lines with PTEN and/or PIK3CA mutation were sensitive to MK-2206. Thus, not all tumors with PTEN/ PIK3CA mutation rely on Akt for oncogenic signaling.

Allosteric mTOR inhibitors have already been shown to have antitumor efficacy in renal carcinoma, neuroendocrine tumors, and breast cancer. It is interesting that some cell lines that were MK-2206 resistant in this study (e.g., MDA-MB-468) are sensitive to allosteric mTOR inhibitors (38). Which tumor types would preferentially benefit from Akt inhibitors rather than mTOR inhibitors is unclear. Furthermore, there are several Akt inhibitors in clinical development; antitumor efficacy may also differ among these drugs. A combination of biomarkers is likely needed to determine the best therapeutic approach in patients with aberrations in PI3K/Akt/mTOR signaling.

Only a few Akt targets have been shown to have isoform specificity to date: p21 CIP, SKP2, and palladin are Akt1 targets, and MDM2 and AS160 are Akt2 targets (39-44). Although Akt regulates cancer cell survival, signaling through Akt1 has been shown to block both cell invasion and migration. Actin-bundling protein palladin inhibits the breast cancer cell invasive phenotype, at least partly through regulation of phosphorylation of palladin by Akt1, whereas Akt2 regulates expression of palladin (35, 41). In our cell lines, MK-2206sensitive cell lines had higher Akt1/2 ratios, however a high Akt1/2 mRNA ratio was not associated with MK-2206 sensitivity in a large cell line panel. The role of individual Akt isoforms in MK-2206 sensitivity needs to be further studied, and if there is an association, its downstream mediators need to be identified.

MK-2206 had a dose-dependent effect on cell signaling and tumor growth. Indeed, although Akt phosphorylation was inhibited with clinically relevant doses, dose escalation had a greater effect on downstream effectors such as 4E-BP1. Apoptosis was only seen with high doses of MK-2206. In xenograft models, furthermore, treatment with low-dose MK-2206, both as a single agent and in combination therapy, inhibited tumor growth. However, higher doses of MK-2206 led to tumor regression. Recently it has been shown that, although cancer cells treated with high doses of Akt inhibitors underwent apoptosis, those treated with moderate doses that only partially inhibited Akt signaling divided asymmetrically to produce an increased population of slowly proliferating $\mathrm{G}_{0}$-like cells, representing a potential mode of therapy resistance (45). This dose dependence should be taken into consideration when dose reductions are considered in clinical trials for toxic effects such as skin rash. pAkt was 
shown to decline in tumor biopsies and in hair follicles in the phase I MK-2206 trial (23). Correlative studies are ongoing in clinical trials to determine whether extent of Akt dephosphorylation and more complete downstream target inhibition correlates with clinical benefit.

MK-2206 was shown recently to be synergistic with several therapeutic agents $(21,36,46-$ 49). Synergy in combinatorial regimens has been attributed to enhanced apoptotic cell death and autophagy (21, 46-49). Moreover, blunting autophagic response to MK-2206 with elongation factor 2 kinase inhibitors has been shown to enhance apoptotic response to MK-2206 (50). Here, we showed synergy between MK-2206 and paclitaxel in vitro, and greater antitumor efficacy in combination of MK-2206 and paclitaxel than either agent alone in vivo. This finding is of particular clinical relevance as paclitaxel is used in the treatment of breast cancer in the adjuvant as well as metastatic setting. Our study shows synergy between MK-2206 and paclitaxel in MK-2206-sensitive but not in MK-2206- resistant breast cancer cell lines. This suggests that even when an Akt inhibitor is used in combination therapy, optimizing patient selection may enhance clinical benefit. Further study is needed to determine the mechanism of this synergy and to identify molecular predictors that can assist in prioritizing therapeutic regimens.

In summary, MK-2206 has antitumor activity alone and in combination with chemotherapy, and this activity may be greater in tumors with PTEN or PIK3CA mutation, supporting the concept of biomarker testing for patient enrichment in clinical trials. However, not all tumors with these aberrations are MK-2206 sensitive, emphasizing the need for additional predictive and pharmacodynamic markers of response.

\section{Supplementary Material}

Refer to Web version on PubMed Central for supplementary material.

\section{Acknowledgments}

The authors thank Kathryn Hale for editorial assistance, and DaRonia Taylor and Vanessa Lerma for assistance in manuscript preparation.

\section{Grant Support}

This work was supported by the Susan G. Komen Foundation for the Cure grant SAC10006 (F. Meric-Bernstam, K.-A. Do); A.M. Gonzalez-Angulo, G.B. Mills, A. Akcakanat, F. Meric-Bernstam, and C.L. Arteaga are supported by a Stand Up To Cancer Dream Team Translational Cancer Research Grant, a Program of the Entertainment Industry Foundation (SU2C-AACR-DT0209 01); Society of Surgical Oncology Clinical Investigator Award in Breast Cancer Research (F. Meric-Bernstam); NIH grant R21 CA159270-01 (F. Meric-Bernstam); National Center for Research Resources grant 3UL1RR024148 (A. Akcakanat, F. Meric-Bernstam, K.-A. Do) and UL1TR000371 (F. Meric-Bernstam, K.-A. Do); The University of Texas MD Anderson Cancer Center support grant (P30 CA016672); NIH F32CA121900 (T.W. Miller), K99CA142899 (T.W. Miller), Breast Cancer Specialized Program of Research Excellence (SPORE) grant P50CA98131, Vanderbilt-Ingram Cancer Center Support Grant P30CA68485; a grant from the Breast Cancer Research Foundation (C.L. Arteaga); ACS Clinical Research Professorship Grant CRP-07-234 (C.L. Arteaga); and the Lee Jeans Translational Breast Cancer Research Program (C.L. Arteaga).

\section{References}

1. Akcakanat A, Zhang L, Tsavachidis S, Meric-Bernstam F. The rapamycin-regulated gene expression signature determines prognosis for breast cancer. Mol Cancer. 2009; 8:75. [PubMed: 19778445]

2. Stemke-Hale K, Gonzalez-Angulo AM, Lluch A, Neve RM, Kuo WL, Davies M, et al. An integrative genomic and proteomic analysis of PIK3CA, PTEN, and AKT mutations in breast cancer. Cancer Res. 2008; 68:6084-6091. [PubMed: 18676830] 
3. Saal LH, Johansson P, Holm K, Gruvberger-Saal SK, She QB, Maurer M, et al. Poor prognosis in carcinoma is associated with a gene expression signature of aberrant PTEN tumor suppressor pathway activity. Proc Natl Acad Sci U S A. 2007; 104:7564-7569. [PubMed: 17452630]

4. Vasudevan KM, Barbie DA, Davies MA, Rabinovsky R, McNear CJ, Kim JJ, et al. AKTindependent signaling downstream of oncogenic PIK3CA mutations in human cancer. Cancer Cell. 2009; 16:21-32. [PubMed: 19573809]

5. Ikenoue T, Kanai F, Hikiba Y, Obata T, Tanaka Y, Imamura J, et al. Functional analysis of PIK3CA gene mutations in human colorectal cancer. Cancer Res. 2005; 65:4562-4567. [PubMed: 15930273]

6. Gymnopoulos M, Elsliger MA, Vogt PK. Rare cancer-specific mutations in PIK3CA show gain of function. Proc Natl Acad Sci U S A. 2007; 104:5569-5574. [PubMed: 17376864]

7. Miller TW, Perez-Torres M, Narasanna A, Guix M, Stal O, Perez-Tenorio G, et al. Loss of Phosphatase and Tensin homologue deleted on chromosome 10 engages ErbB3 and insulin-like growth factor-I receptor signaling to promote antiestrogen resistance in breast cancer. Cancer Res. 2009; 69:4192-4201. [PubMed: 19435893]

8. Miller TW, Hennessy BT, Gonzalez-Angulo AM, Fox EM, Mills GB, Chen H, et al. Hyperactivation of phosphatidylinositol-3 kinase promotes escape from hormone dependence in estrogen receptor-positive human breast cancer. J Clin Invest. 2010; 120:2406-2413. [PubMed: 20530877]

9. Berns K, Horlings HM, Hennessy BT, Madiredjo M, Hijmans EM, Beelen K, et al. A functional genetic approach identifies the PI3K pathway as a major determinant of trastuzumab resistance in breast cancer. Cancer Cell. 2007; 12:395-402. [PubMed: 17936563]

10. Jensen JD, Knoop A, Laenkholm AV, Grauslund M, Jensen MB, Santoni-Rugiu E, et al. PIK3CA mutations, PTEN, and pHER2 expression and impact on outcome in HER2-positive early-stage breast cancer patients treated with adjuvant chemotherapy and trastuzumab. Ann Oncol. 2012; 23:2034-2042. [PubMed: 22172323]

11. Nagata Y, Lan KH, Zhou X, Tan M, Esteva FJ, Sahin AA, et al. PTEN activation contributes to tumor inhibition by trastuzumab, and loss of PTEN predicts trastuzumab resistance in patients. Cancer Cell. 2004; 6:117-127. [PubMed: 15324695]

12. Moreno A, Akcakanat A, Munsell MF, Soni A, Yao JC, Meric-Bernstam F. Antitumor activity of rapamycin and octreotide as single agents or in combination in neuroendocrine tumors. Endocr Relat Cancer. 2008; 15:257-266. [PubMed: 18310292]

13. Mondesire WH, Jian W, Zhang H, Ensor J, Hung MC, Mills GB, et al. Targeting mammalian target of rapamycin synergistically enhances chemotherapy-induced cytotoxicity in breast cancer cells. Clin Cancer Res. 2004; 10:7031-7042. [PubMed: 15501983]

14. Oda K, Stokoe D, Taketani Y, McCormick F. High frequency of coexistent mutations of PIK3CA and PTEN genes in endometrial carcinoma. Cancer Res. 2005; 65:10669-10673. [PubMed: 16322209]

15. Tibes R, Qiu Y, Lu Y, Hennessy B, Andreeff M, Mills GB, et al. Reverse phase protein array: validation of a novel proteomic technology and utility for analysis of primary leukemia specimens and hematopoietic stem cells. Mol Cancer Ther. 2006; 5:2512-2521. [PubMed: 17041095]

16. Hennessy BT, Lu Y, Poradosu E, Yu Q, Yu S, Hall H, et al. Pharma-codynamic markers of perifosine efficacy. Clin Cancer Res. 2007; 13:7421-7431. [PubMed: 18094426]

17. Gonzalez-Angulo AM, Hennessy BT, Meric-Bernstam F, Sahin A, Liu W, Ju Z, et al. Functional proteomics can define prognosis and predict pathologic complete response in patients with breast cancer. Clin Proteomics. 2011; 8:11. [PubMed: 21906370]

18. Luyimbazi D, Akcakanat A, McAuliffe PF, Zhang L, Singh G, Gon-zalez-Angulo AM, et al. Rapamycin regulates stearoyl CoA desaturase 1 expression in breast cancer. Mol Cancer Ther. 2010; 9:2770-2784. [PubMed: 20876744]

19. Hu J, Zou F, Wright FA. Practical FDR-based sample size calculations in microarray experiments. Bioinformatics. 2005; 21:3264-3272. [PubMed: 15932903]

20. Benjamini Y, Hochberg Y. Controlling the false discovery rate: a practical and powerful approach to multiple testing. J R Statist Soc B. 1995; 57:289-300.

21. Hirai H, Sootome H, Nakatsuru Y, Miyama K, Taguchi S, Tsujioka K, et al. MK-2206, an allosteric Akt inhibitor, enhances antitumor efficacy by standard chemotherapeutic agents or 
molecular targeted drugs in vitro and in vivo. Mol Cancer Ther. 2010; 9:1956-1967. [PubMed: 20571069]

22. Perren A, Weng LP, Boag AH, Ziebold U, Thakore K, Dahia PL, et al. Immunohistochemical evidence of loss of PTEN expression in primary ductal adenocarcinomas of the breast. Am J Pathol. 1999; 155:1253-1260. [PubMed: 10514407]

23. Yap TA, Yan L, Patnaik A, Fearen I, Olmos D, Papadopoulos K, et al. First-in-man clinical trial of the oral pan-AKT inhibitor MK-2206 in patients with advanced solid tumors. J Clin Oncol. 2011; 29:4688-4695. [PubMed: 22025163]

24. Meric-Bernstam F, Akcakanat A, Chen H, Do KA, Sangai T, Adkins F, et al. PIK3CA/PTEN mutations and Akt activation as markers of sensitivity to allosteric mTOR inhibitors. Clin Cancer Res. 2012; 18:1777-1789. [PubMed: 22422409]

25. Barretina J, Caponigro G, Stransky N, Venkatesan K, Margolin AA, Kim S, et al. The Cancer Cell Line Encyclopedia enables predictive modelling of anticancer drug sensitivity. Nature. 2012; 483:603-607. [PubMed: 22460905]

26. Broad-Novartis Cancer Cell Line Encyclopedia (CCLE). http://www.broadinstitute.org/ccle

27. Forbes SA, Tang G, Bindal N, Bamford S, Dawson E, Cole C, et al. COSMIC (the Catalogue of Somatic Mutations in Cancer): a resource to investigate acquired mutations in human cancer. Nucleic Acids Res. 2010; 38:D652-D657. [PubMed: 19906727]

28. Gonzalez-Angulo AM, Ferrer-Lozano J, Stemke-Hale K, Sahin A, Liu S, Barrera JA, et al. PI3K pathway mutations and PTEN levels in primary and metastatic breast cancer. Mol Cancer Ther. 2011; 10:1093-1101. [PubMed: 21490305]

29. Datta SR, Dudek H, Tao X, Masters S, Fu H, Gotoh Y, et al. Akt phosphorylation of BAD couples survival signals to the cell-intrinsic death machinery. Cell. 1997; 91:231-241. [PubMed: 9346240]

30. del, Peso L.; Gonzalez-Garcia, M.; Page, C.; Herrera, R.; Nunez, G. Inter-leukin-3-induced phosphorylation of BAD through the protein kinase Akt. Science. 1997; 278:687-689. [PubMed: 9381178]

31. Saal LH, Gruvberger-Saal SK, Persson C, Lovgren K, Jumppanen M, Staaf J, et al. Recurrent gross mutations of the PTEN tumor suppressor gene in breast cancers with deficient DSB repair. Nat Genet. 2008; 40:102-107. [PubMed: 18066063]

32. Gewinner C, Wang ZC, Richardson A, Teruya-Feldstein J, Etemadmo-ghadam D, Bowtell D, et al. Evidence that inositol polyphosphate 4-phosphatase type II is a tumor suppressor that inhibits PI3K signaling. Cancer Cell. 2009; 16:115-125. [PubMed: 19647222]

33. Gao T, Furnari F, Newton AC. PHLPP: a phosphatase that directly dephosphorylates Akt, promotes apoptosis, and suppresses tumor growth. Mol Cell. 2005; 18:13-24. [PubMed: 15808505]

34. Nitsche C, Edderkaoui M, Moore RM, Eibl G, Kasahara N, Treger J, et al. The phosphatase PHLPP1 regulates Akt2, promotes pancreatic cancer cell death, and inhibits tumor formation. Gastroenterology. 2012; 142:377-387. e1-5. [PubMed: 22044669]

35. Chin YR, Toker A. Akt2 regulates expression of the actin-bundling protein palladin. FEBS Lett. 2010; 584:4769-4774. [PubMed: 21050850]

36. Liu R, Liu D, Xing M. The Akt inhibitor MK2206 synergizes, but perifosine antagonizes, the BRAF(V600E) inhibitor PLX4032 and the MEK1/2 inhibitor AZD6244 in the inhibition of thyroid cancer cells. J Clin Endocrinol Metab. 2012; 97:E173-E182. [PubMed: 22090271]

37. M.D. Anderson Cancer Center. ClinicalTrials.gov [Internet]. Bethesda MD; National Library of Medicine (US: 2000. Akt inhibitor MK-2206 in patients with advanced breast cancer who have tumors with a PIK3CA mutation and/or PTEN loss. Available from: http://clinicaltrials.gov/ct2/ show/NCT01277757 NLM Identifier: NCT01277757 [[cited 2012 Sep 12]]

38. Noh WC, Mondesire WH, Peng J, Jian W, Zhang H, Dong J, et al. Determinants of rapamycin sensitivity in breast cancer cells. Clin Cancer Res. 2004; 10:1013-1023. [PubMed: 14871980]

39. Heron-Milhavet L, Franckhauser C, Rana V, Berthenet C, Fisher D, Hemmings BA, et al. Only Akt1 is required for proliferation, while Akt2 promotes cell cycle exit through p21 binding. Mol Cell Biol. 2006; 26:8267-8280. [PubMed: 16982699] 
40. Gao D, Inuzuka H, Tseng A, Chin RY, Toker A, Wei W. Phosphorylation by Akt1 promotes cytoplasmic localization of Skp2 and impairs APCCdh1-mediated Skp2 destruction. Nat Cell Biol. 2009; 11:397-408. [PubMed: 19270695]

41. Chin YR, Toker A. The actin-bundling protein palladin is an Akt1-specific substrate that regulates breast cancer cell migration. Mol Cell. 2010; 38:333-344. [PubMed: 20471940]

42. Bouzakri K, Zachrisson A, Al-Khalili L, Zhang BB, Koistinen HA, Krook A, et al. siRNA-based gene silencing reveals specialized roles of IRS-1/ Akt2 and IRS-2/Akt1 in glucose and lipid metabolism in human skeletal muscle. Cell Metab. 2006; 4:89-96. [PubMed: 16814735]

43. Gonzalez E, McGraw TE. Insulin-modulated Akt subcellular localization determines Akt isoformspecific signaling. Proc Natl Acad Sci U S A. 2009; 106:7004-7009. [PubMed: 19372382]

44. Brognard J, Sierecki E, Gao T, Newton AC. PHLPP and a second isoform, PHLPP2, differentially attenuate the amplitude of Akt signaling by regulating distinct Akt isoforms. Mol Cell. 2007; 25:917-931. [PubMed: 17386267]

45. Dey-Guha I, Wolfer A, Yeh AC, Albeck JG, Darp R, Leon E, et al. Asymmetric cancer cell division regulated by AKT. Proc Natl Acad Sci U S A. 2011; 108:12845-12850. [PubMed: 21757645]

46. Balasis ME, Forinash KD, Chen YA, Fulp WJ, Coppola D, Hamilton AD, et al. Combination of farnesyltransferase and Akt inhibitors is synergistic in breast cancer cells and causes significant breast tumor regression in ErbB2 transgenic mice. Clin Cancer Res. 2011; 17:2852-2862. [PubMed: 21536547]

47. Meng J, Dai B, Fang B, Bekele BN, Bornmann WG, Sun D, et al. Combination treatment with MEK and AKT inhibitors is more effective than each drug alone in human non-small cell lung cancer in vitro and in vivo. PLoS One. 2010; 5:e14124. [PubMed: 21124782]

48. Chen KF, Chen HL, Tai WT, Feng WC, Hsu CH, Chen PJ, et al. Activation of phosphatidylinositol 3-kinase/Akt signaling pathway mediates acquired resistance to sorafenib in hepatocellular carcinoma cells. J Pharmacol Exp Ther. 2011; 337:155-161. [PubMed: 21205925]

49. Cheng Y, Zhang Y, Zhang L, Ren X, Huber-Keener KJ, Liu X, et al. MK-2206, a novel allosteric inhibitor of Akt, synergizes with gefitinib against malignant glioma via modulating both autophagy and apoptosis. Mol Cancer Ther. 2012; 11:154-164. [PubMed: 22057914]

50. Cheng Y, Ren X, Zhang Y, Patel R, Sharma A, Wu H, et al. eEF-2 kinase dictates cross-talk between autophagy and apoptosis induced by Akt inhibition, thereby modulating cytotoxicity of novel Akt inhibitor MK-2206. Cancer Res. 2011; 71:2654-2663. [PubMed: 21307130] 


\section{Translational Relevance}

Activated Akt signaling is a significant contributor to the pathogenesis of breast cancer. $P T E N$, a negative regulator of PI3K/Akt signaling, is mutated or decreased, and PIK3CA is frequently mutated in multiple cancer lineages. In this study, we showed that cell lines with PTEN or PIK3CA mutations are more sensitive to MK-2206, a selective allosteric inhibitor of Akt. PTEN knockdown or introducing PIK3CA mutations in isogenic cell lines increased MK-2206 sensitivity. MK-2206 is synergistic with paclitaxel in vitro and enhances paclitaxel-mediated growth inhibition in vivo. These data show antitumor efficacy of MK-2206 in vitro and in vivo, and provide support for testing PTEN loss and PI3KCA mutations as potential predictors of response to MK-2206. 
A
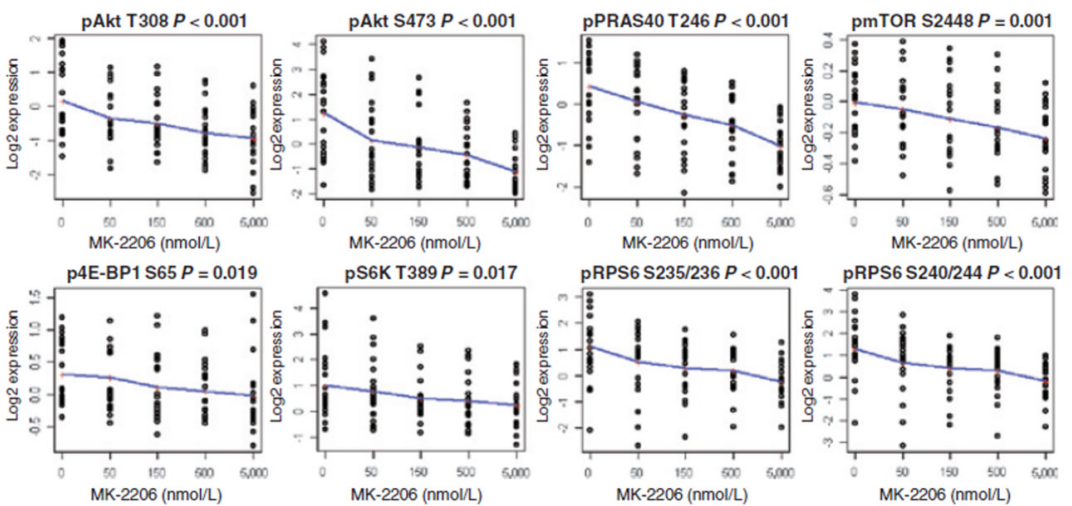

PS6K T389P $=0.017$
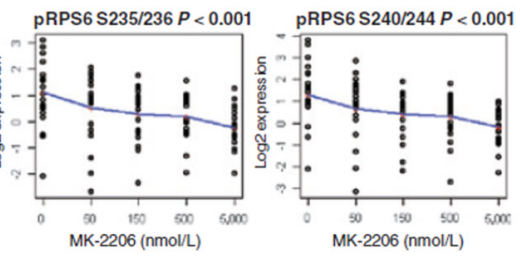

B
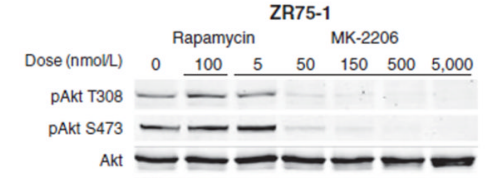

Akt $\longrightarrow \longrightarrow$

pGSKз乃S9 $\div-\div$

GSK3 $=0=$

PPRAS T246 $\mathrm{C}=-$ DFOXO1/FOXO3a

$\mathrm{T} 24 / \mathrm{T} 32$
pBad $\mathrm{S} 136$

$$
\text { pBad } \$ 112
$$

PMTOR S2448

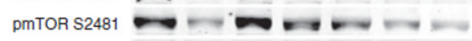

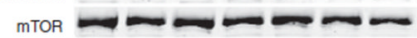

pS6K T389 :-

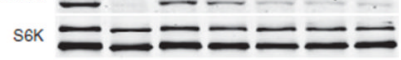

p-s6s235/236 -

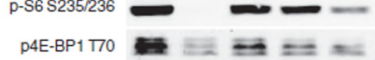

P4E-BP1S65 - - - -

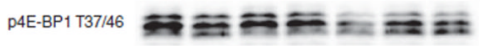

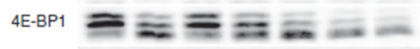

D

C

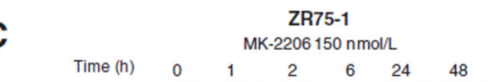

Actin $-\div-\div-$
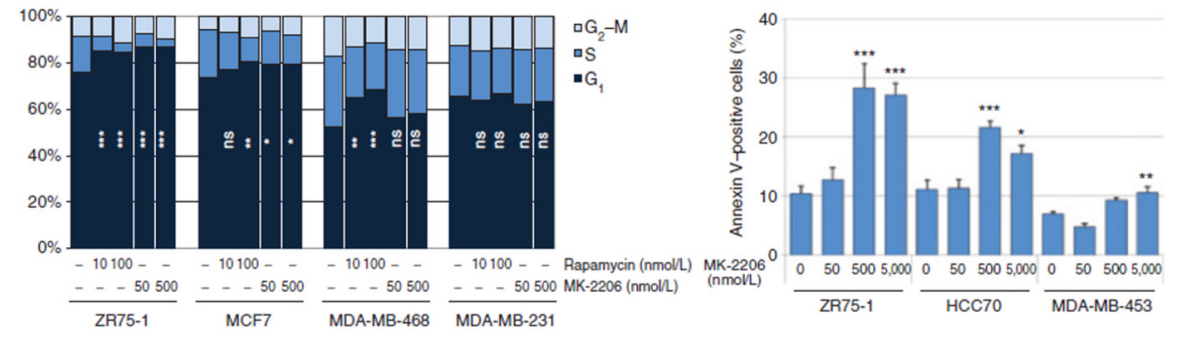

Figure 1.

MK-2206 inhibits Akt signaling, causes cell-cycle arrest and apoptosis. A, 7 cancer cell lines were treated with vehicle or increasing doses of MK-2206 for 24 hours.

Phosphoprotein levels were assessed by RPPA. Each dot indicates triplicated samples and the solid line connects the means. B, ZR75-1 cells were treated with vehicle, rapamycin 100 $\mathrm{nmol} / \mathrm{L}$, or increasing concentrations of MK-2206 for 24 hours. Western blotting was conducted to assess Akt signaling. C, ZR75-1 cells were treated with MK-2206 $150 \mathrm{nmol} / \mathrm{L}$ and collected after indicated hours. Akt signaling was assessed by Western blotting. D, breast cancer cell lines were treated with vehicle, rapamycin $(10$ or $100 \mathrm{nmol} / \mathrm{L})$, or MK-2206 (50 or $500 \mathrm{nmol} / \mathrm{L}$ ) in triplicate for 96 hours, and percentages of cells in $\mathrm{G}_{1}$ 
(navy), $\mathrm{S}$ (blue), and $\mathrm{G}_{2}-\mathrm{M}$ (light blue) phases of the cell cycle were determined by flow cytometry. The percentages of cells in $G_{1}$ phase in each treatment group were compared (*,P $<0.05 ; * *, P<0.01 ; * * *, P<0.001$; ns, not significant vs. control). E, MK-2206-sensitive breast cancer cell lines were treated with vehicle or MK-2206 $(50,500$, or 5,000 nmol/L) for 72 hours in triplicate. The percentages of annexin $\mathrm{V}$-positive cells were determined with flow cytometry and were compared (*, $P<0.05$; **, $P<0.01$; ***, $P<0.001$, vs. control). 
A

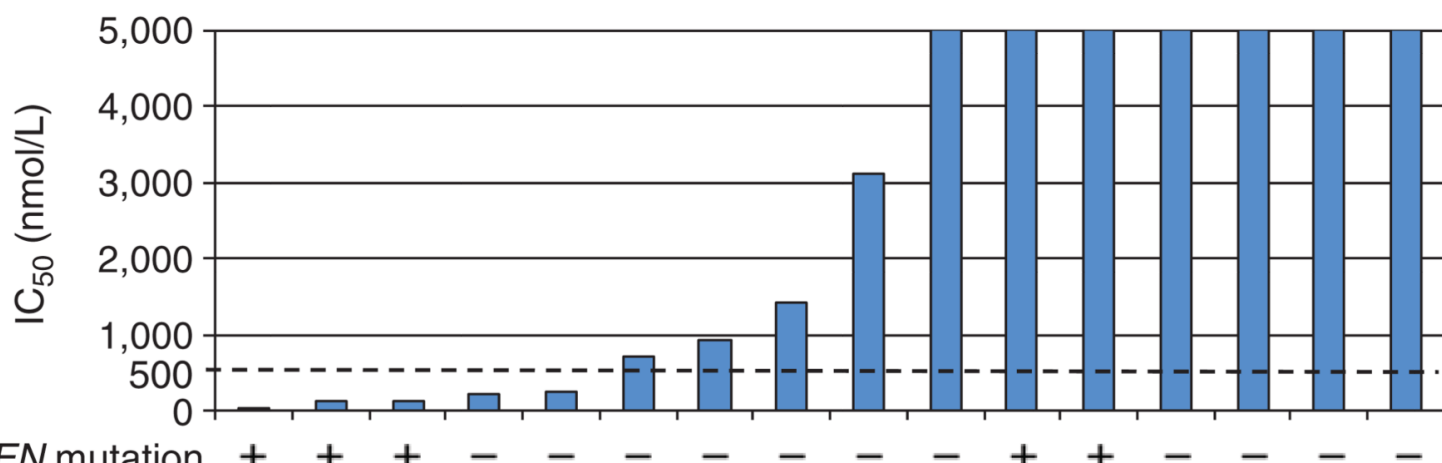

PTEN mutation $+++--\quad-\quad-\quad-\quad+++-$

PIK3CA mutation --+++-++---

RAS/RAF mutation $+-c_{-}-c_{-}-c_{-}--+-+$

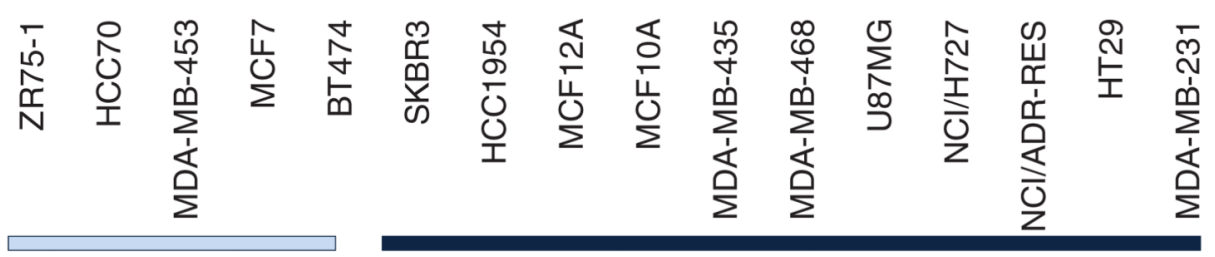

MK-2206-sensitive

MK-2206-resistant

B

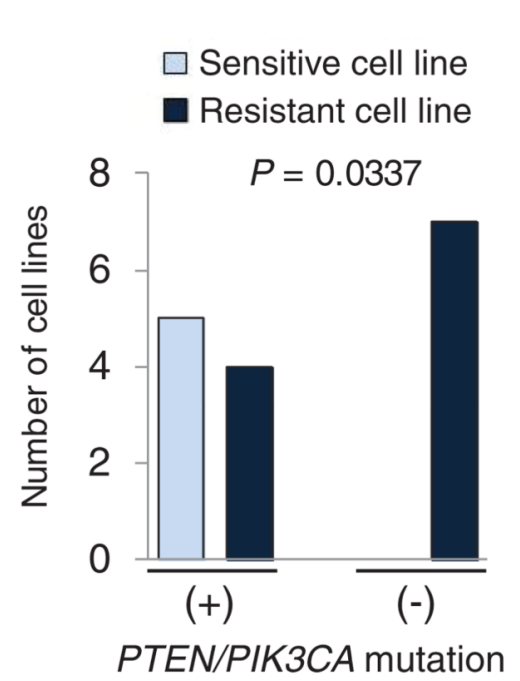

Sensitive cell line

C

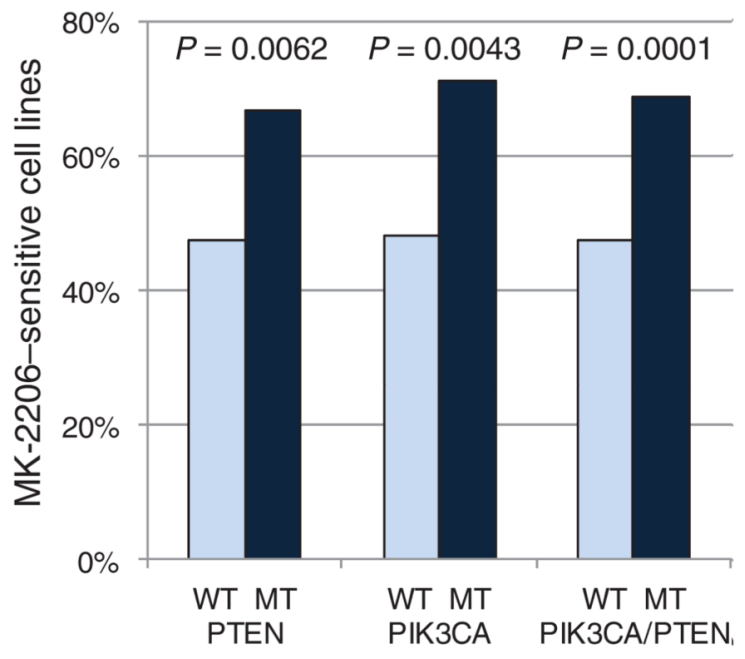

Figure 2.

PTEN and PIK3CA status is associated with MK-2206 sensitivity. A, 16 cell lines with varying PIK3CA, PTEN, and RAS/RAF status were treated with increasing doses of MK-2206, and $\mathrm{IC}_{50}$ was determined by SRB assay. B, 5 of the 16 cell lines were MK-2206 sensitive $\left(\mathrm{IC}_{50}<500 \mathrm{nmol} / \mathrm{L}\right)$. MK-2206 sensitivity in cell lines with PTEN or PIK3CA mutation was compared to sensitivity of PTEN and PIK3CA wild-type cells. C, 233 of the 444 cell lines in the COSMIC were MK-2206 sensitive $\left(\mathrm{IC}_{50}<\right.$ mean $\mathrm{IC}_{50}$ value of PTEN/ PIK3CA wild type). MK-2206 sensitivity in cells with PTEN or PIK3CA mutation was compared with sensitivity of PTEN and PIK3CA wild-type cells. WT, wild-type; MT, mutant. 
A

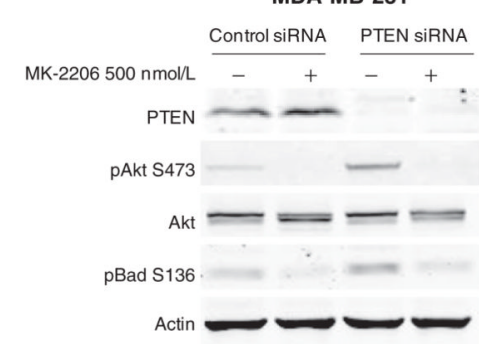

B

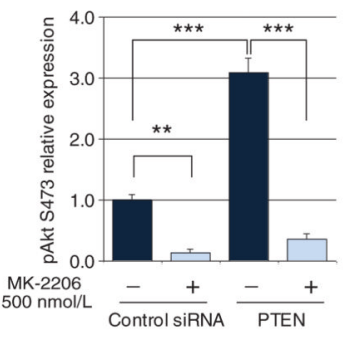

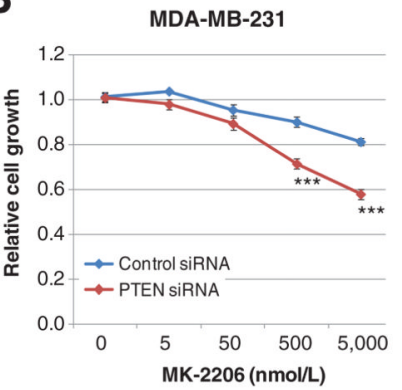

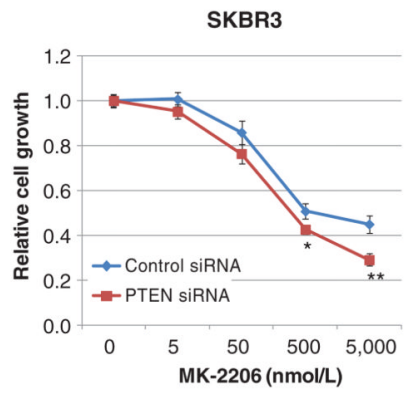

C

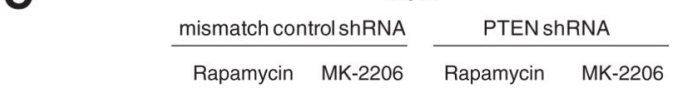

$\begin{array}{rllllll}\text { Dose }(\mathrm{nmol} / \mathrm{L}) & 0 \quad 100 & 50 \quad 500 & 0 & 100 & 50 \quad 500 \\ \text { PTEN } & - & & \end{array}$

PTEN

pAkt T308

pAkt S473

Akt

Actin

D

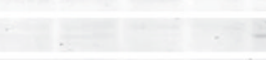

Dose (nmol/L)
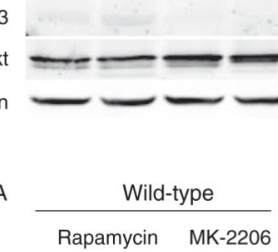

Rapamycin MK-2206

pAkt T308

$0 \quad 100 \quad 50 \quad 500$

pAkt S473

Akt

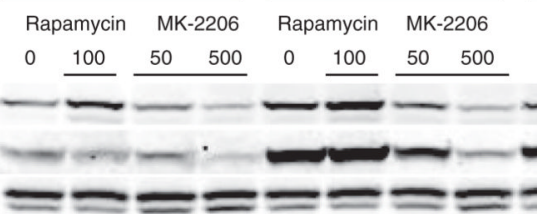

Actin

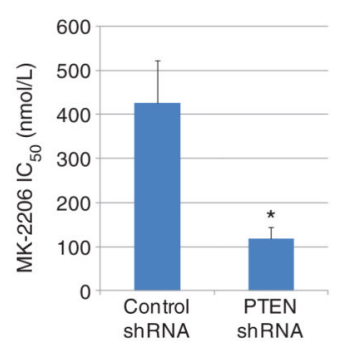

MCF10A

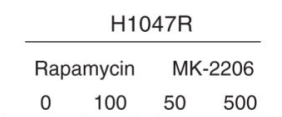

$0 \quad 100 \quad 50 \quad 500$

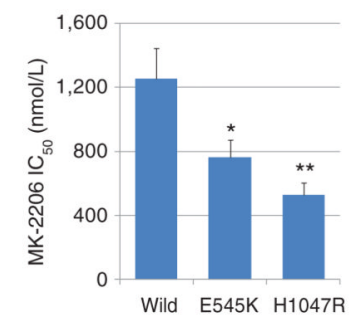

Figure 3.

PTEN loss and PIK3CA mutation confer MK-2206 sensitivity. A, MDA-MB-231 cells were treated with control or PTENsiRNAfor24 hours and were subsequently treated with vehicle or MK-2206 $500 \mathrm{nmol} / \mathrm{L}$ for 24 hours. pAkt S473 and pBad S136 levels were assessed by Western blotting. The relative expression of pAkt $\mathrm{S} 473$ was calculated $(* * P<0.01 ; * *, P<$ 0.001 vs. indicated in the graph). B, MDA-MB-231 and SKBR3 cells were treated with control or PTEN siRNA for 24 hours and were subsequently treated with MK-2206 for 96 hours. Cell growth in response to MK-2206 treatment was assessed by SRB assay and was compared at each MK-2206 concentration ( $* P=0.0410 ; * * P=0.0038 ; * * * P<0.0001)$. C, MCF7 cells transfected with mismatch control or PTEN shRNA were cultured in phenol red free medium supplemented with $2 \%$ charcoal-stripped FBS for 24 hours and subsequently treated with vehicle, rapamycin $100 \mathrm{nmol} / \mathrm{L}$, or MK-2206 (50 or $500 \mathrm{nmol} / \mathrm{L}$ ) for 24 hours. pAkt T308 and S473 levels were assessed by Western blotting. The graph represents MK-2206 IC50 under estrogen-depleted conditions (*, $P=0.0074)$. D, MCF10A cells stably transfected with PIK3CA wild-type, E545K mutant, or H1047R mutant were treated with vehicle, rapamycin $100 \mathrm{nmol} / \mathrm{L}$, or MK-2206 (50 or $500 \mathrm{nmol} / \mathrm{L}$ ) for 24 hours. pAkt T308 and S473 were assessed by Western blotting. The graph represents MK-2206 IC50 for each transfected cell line (*, $P<0.05 ; * * P<0.01$ vs. control). 
A
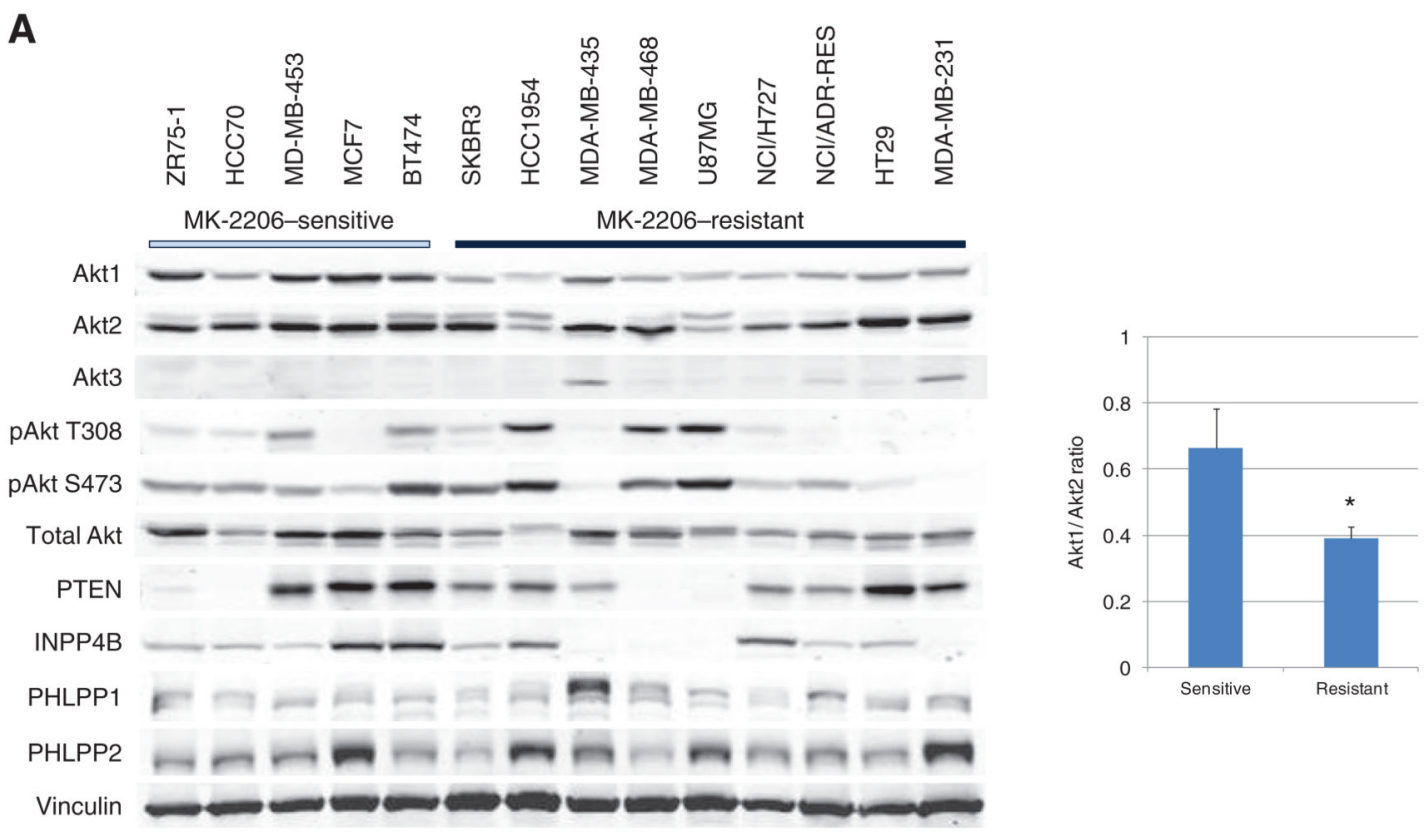

B

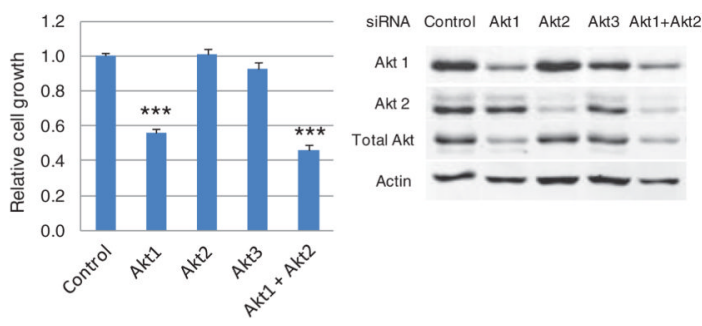

$\mathrm{HCC} 1954\left(\mathrm{MK}-2206 \mathrm{IC}_{50}=944 \mathrm{nmol} / \mathrm{L}\right)$

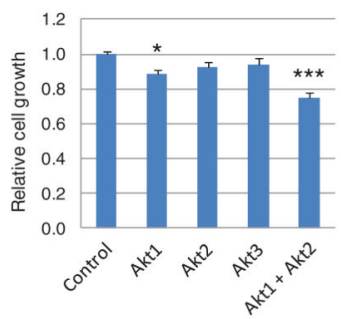

MDA-MB-468 (MK-2206 IC $\left.\mathrm{I}_{50}=2,725 \mathrm{nmol} / \mathrm{L}\right)$

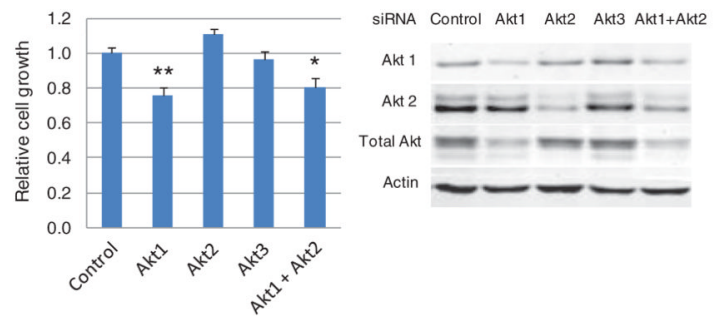

MDA-MB-231 (MK-2206 IC $\left.{ }_{50}>10,000 \mathrm{nmol} / \mathrm{L}\right)$

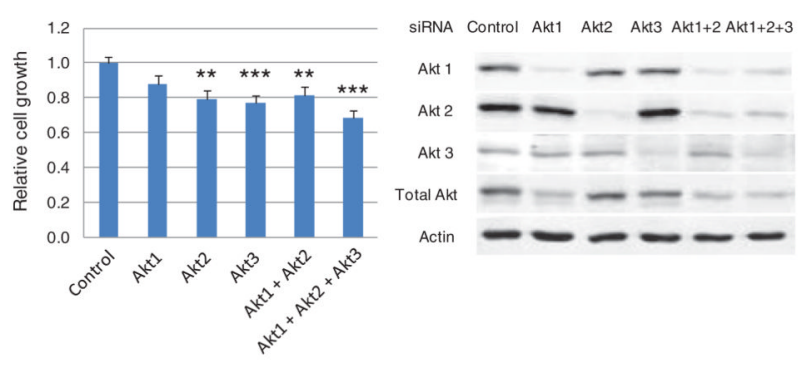

Figure 4.

MK-2206 sensitivity is associated with Akt-dependent growth. A, baseline expression of Akt isoforms, pAkt, PTEN, INPP4B, and PHLPPs was assessed by Western blotting. Akt1/ Akt2 ratios in MK-2206-sensitive and -resistant cell lines were compared (,$P=0.0163$ ). B, 4 breast cancer cell lines were treated with control siRNA or siRNA to different isoforms for 96 hours. Western blotting was conducted to assess expression of Akt and its isoforms. Cell growth was assessed by SRB assay (*, $P<0.05 ; * * P<0.01 ; * * *, P<0.001$ vs. control). 
A

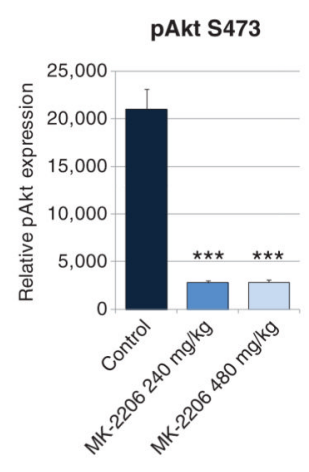

C

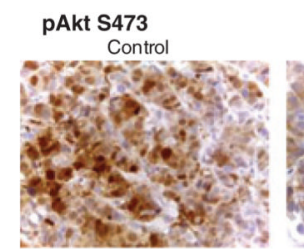

Ki-67

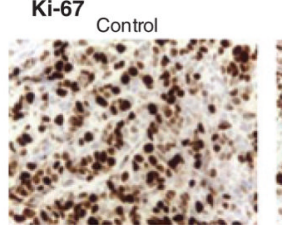

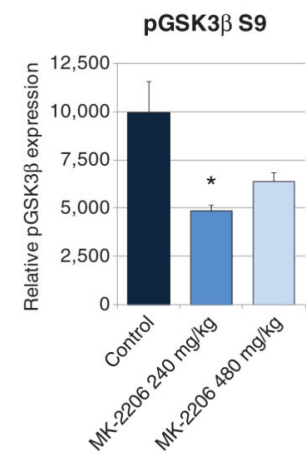

B

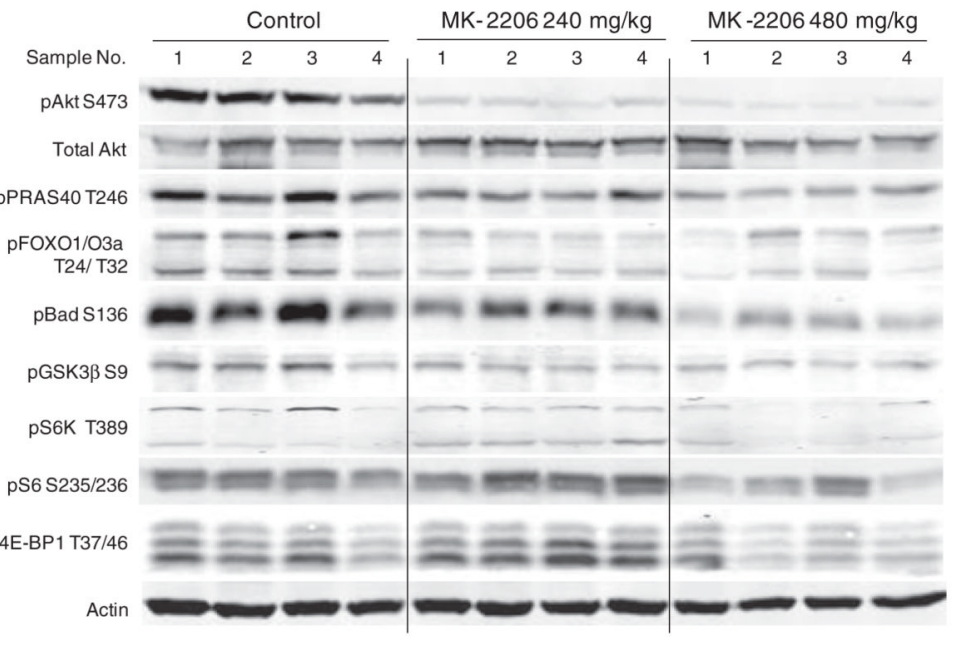

MK-2206 $240 \mathrm{mg} / \mathrm{kg}$

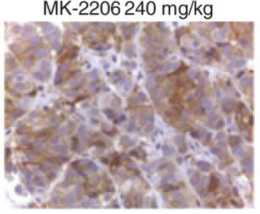

MK-2206 $480 \mathrm{mg} / \mathrm{kg}$

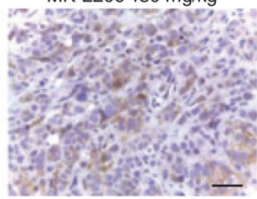

MK-2206 240 mg/kg

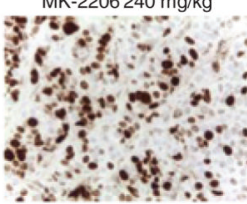

MK-2206 $480 \mathrm{mg} / \mathrm{kg}$
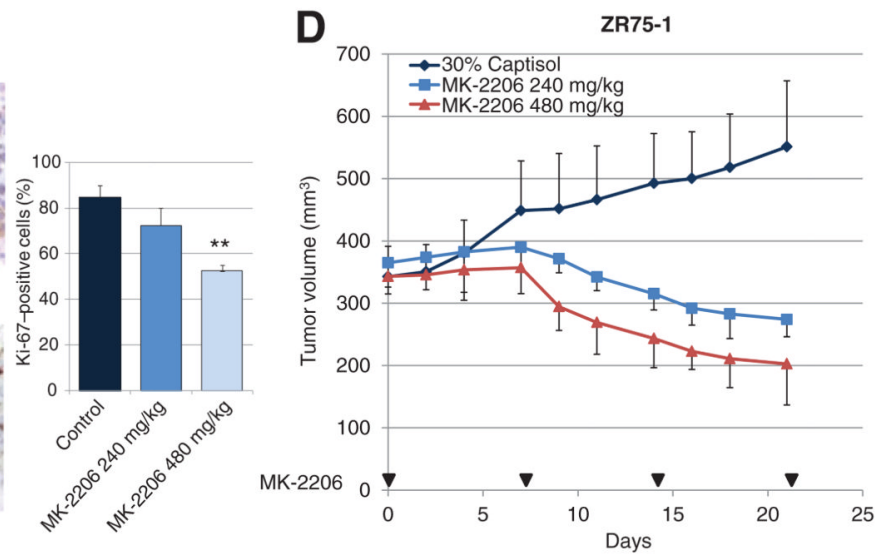

Figure 5.

MK-2206 inhibits Akt signaling and tumor growth in vivo. Nu/nu mice bearing ZR75-1 xenografts were treated with vehicle MK-2206 $240 \mathrm{mg} / \mathrm{kg}$, or MK-2206 $480 \mathrm{mg} / \mathrm{kg}$. Four randomly selected tumors from each group were harvested 24 hours after the 4th treatment. A, pAkt S473, pGSK3 $\beta$ S9, and total Akt expression were assessed by MSD assay. Relative expression as the ratio of pAkt S473 or pGSK3 $\beta$ S 9 to total Akt was calculated $(*, P<0.05$; $* * *, P<0.001$ vs. control). B, the same lysates were assessed by Western blotting for Akt signaling. C, expression of pAkt S473 and Ki-67 was assessed immunohistochemically. Scale bar, $0.02 \mathrm{~mm}$. Percentage of Ki-67 cells in each treatment group were compared (**, $P$ $<0.01$; vs. control). D, the graph represents mean tumor volume of ZR75-1. 
A
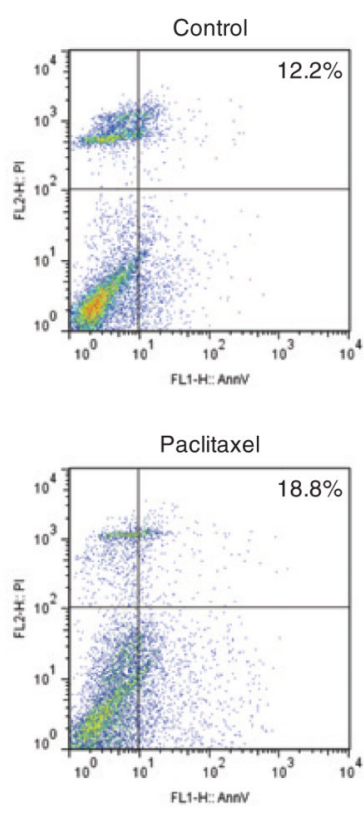

D

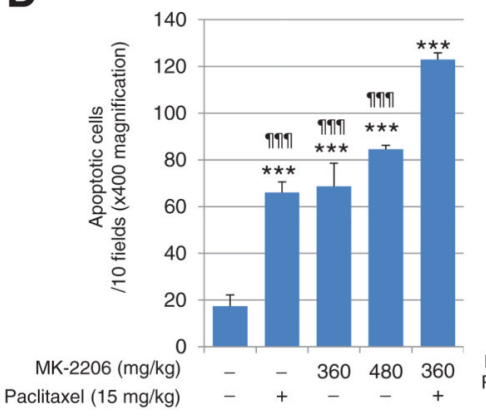

ZR75-1
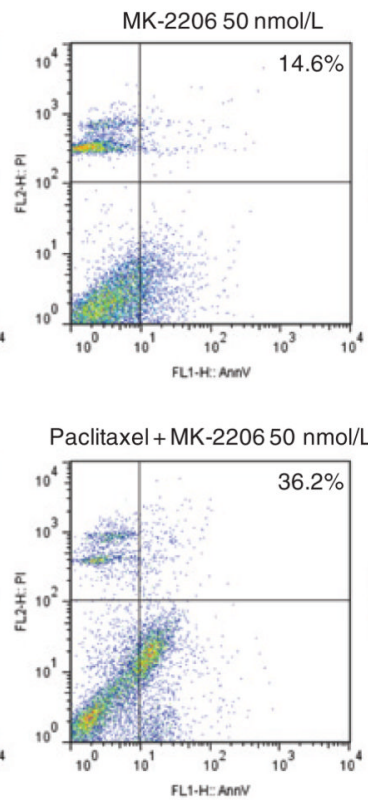

E
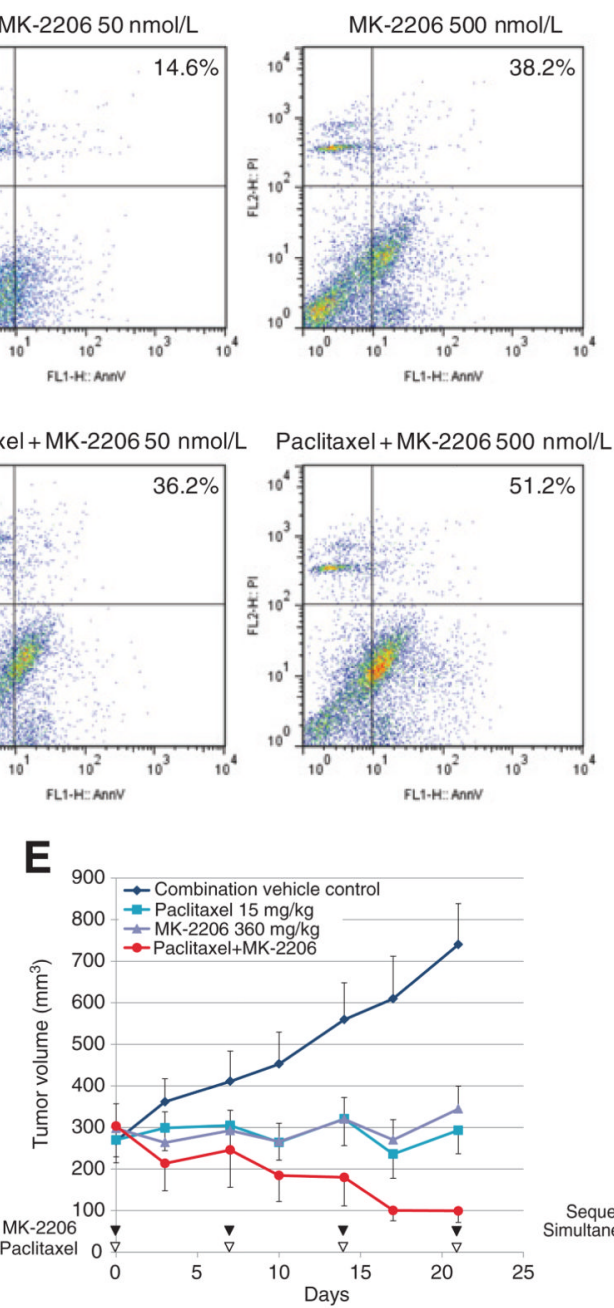

B

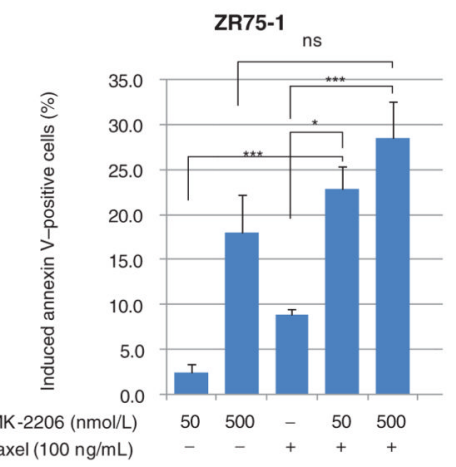
Paclitaxel $(100 \mathrm{ng} / \mathrm{mL})$

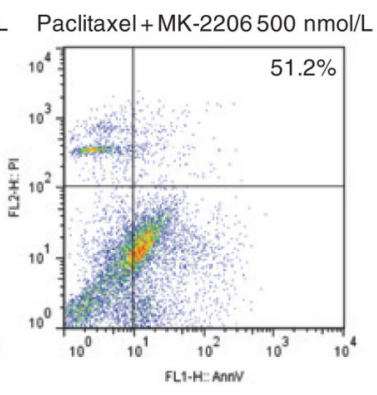

\section{C}

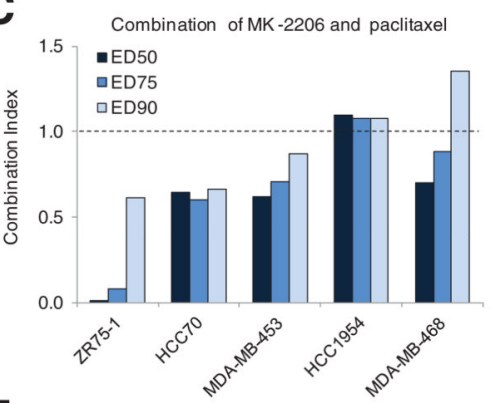

F

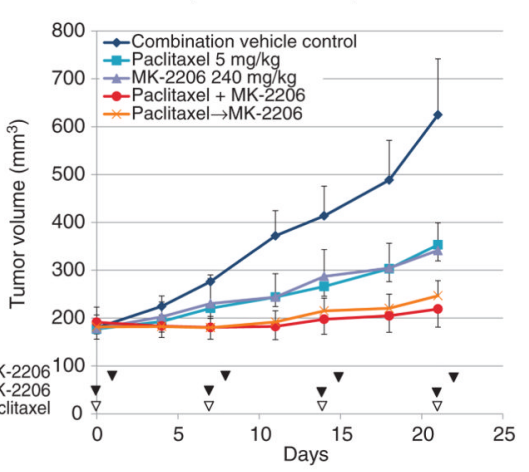

Figure 6.

MK-2206 is synergistic with paclitaxel. A, annexin V-positive cell populations induced by therapy were determined by comparing with cells treated with $0.1 \%$ DMSO as a baseline. Apoptosis induced by MK-2206 or paclitaxel or a combination of the 2 were compared (*,P< 0.05 ; ***, $P<0.001$; ns, not significant, vs. indicated in the graph). B, ZR75-1 cells were treated with MK-2206 and/or paclitaxel for 72 hours, and apoptotic cells were determined with flow cytometry. The populations of annexin $\mathrm{V}$-positive cells are shown in the top right corner of each panel. C, 5 breast cancer cell lines were treated with MK-2206 and paclitaxel simultaneously for 96 hours. The effect on cell growth was assessed by SRB assay, and CI values were calculated. The graph represents the CI of MK-2206 and paclitaxel at ED50, ED75, and ED90. CI < 1.0 represents synergy. D, the apoptosis induction in vivo was assessed by TUNEL. TUNEL-positive cells in 10 fields $(\times 400$ magnification) were compared in each treatment group. The graph represents mean number of apoptotic cells stained with TUNEL ( $* * *, P<0.001$; vs. control, and TIIII, $P<0.001$; vs. combination). E, mice bearing ZR75-1 xenografts were treated with vehicle, paclitaxel 15 $\mathrm{mg} / \mathrm{kg}, \mathrm{MK}-2206360 \mathrm{mg} / \mathrm{kg}$, or a combination of paclitaxel and MK-2206 at the same doses. F, mice bearing ZR75-1 xenografts were treated with vehicle, paclitaxel $5 \mathrm{mg} / \mathrm{kg}$, 
MK-2206 240 mg/kg, paclitaxel and MK-2206 synchronously (paclitaxel+MK-2206), or paclitaxel and MK-2206 sequentially (paclitaxel $\rightarrow$ MK-2206). 